\title{
Validity and Reliability of Smartphones in Assessing Spinal Kinematics: A Systematic Review and Meta-analysis
}

\author{
Juliana A. Sedrez, PhD, Tassia S. Furlanetto, PhD, Grazielle M. Gelain, BSc(Chiro), and \\ Claudia T. Candotti, PhD
}

\begin{abstract}
Objective: Advances in mobile technology have led to the development of smartphones, whose applications present numerous utilities, such as the analysis of human movement based on inertial sensors. The purpose of this review was to investigate validity and reliability of smartphones in assessing the kinematics of the human spine.

Methods: A systematic search was performed on MEDLINE, Embase, Scopus, and LILACS databases, as well as manual searches. The included studies evaluated psychometric properties of smartphones in assessing kinematic variables of the spine (range of motion [ROM], speed, and acceleration). Two independent reviewers performed the selection, reading, data extraction, and risk of bias assessment of the studies.

Results: Of the 2651 articles initially found, 9 were included and had their results for ROM analyzed. The metaanalyses for validity showed very high correlation coefficients in the evaluation of cervical flexion, extension, and lateral flexion; high ones in the evaluation of cervical rotation; and also high ones for intrarater and interrater reproducibility of all cervical movements. The meta-analyses for interrater reproducibility showed high correlation coefficients in the evaluation of lumbar flexion and very high ones for intrarater reproducibility.

Conclusion: The use of smartphones for assessing the ROM of cervical flexion, extension, and lateral flexion and lumbar flexion is feasible. Their use for assessing thoracic rotation is potentially viable, but further validation studies are still needed to ensure a safe use. There is a lack of validation studies that evaluate the applicability of this device in assessing other kinematic characteristics, such as speed and acceleration. (J Manipulative Physiol Ther 2020;43;635645)

Key Indexing Terms: Smartphone; Range of Motion, Articular; Reproducibility of Results; Meta-Analysis
\end{abstract}

\section{INTRODUCTION}

Musculoskeletal ailments, in particular spinal pain, are a problem in modern society. ${ }^{1}$ Efforts have been made to develop an adequate model of assessment of the spine for taking better care of these patients. ${ }^{2}$ In clinical practice, the assessment of spinal movements is essential. ${ }^{3}$ However, a 3-dimensional video system analysis is unfeasible at the clinical setting because it requires a large physical space and user expertise for data collection and analysis, beyond

Graduate Program in Human Movement Sciences, Universidade Federal do Grande do Sul, Porto Alegre, Rio Grande do Sul, Brazil.

Corresponding author: Juliana A. Sedrez, PhD, Av. Domingos de Almeida, 2187, Bairro Areal, Pelotas, RS, Brazil, CEP 96085470.

(e-mail: julianasedrez@gmail.com).

Paper submitted March 19, 2019; in revised form June 1, 2019; accepted October 10, 2019.

$0161-4754$

(C) 2020 by National University of Health Sciences.

https://doi.org/10.1016/j.jmpt.2019.10.012 being expensive. ${ }^{4}$ Nevertheless, health professionals need practicable alternatives based on valid and reproducible instruments for motion assessment of the spine.

Currently, the smartphone has been described as a tool for motion analysis. ${ }^{2,5,6}$ The reason is that smartphones are equipped with advanced computational features, global positioning system receivers, and inertial sensors. ${ }^{7}$ In addition, they run several software programs, called applications, which generally use accelerometers to measure the inclination of the device and enable angular measurements. ${ }^{8}$ More recently, applications measure the use of the inertial sensors of the smartphones as inclinometers. ${ }^{9}$ Thus, these portable devices constitute a powerful tool, not only because they contains high-quality triaxial accelerometers, but also because they have high computational power, data storage space, and Internet connectivity. ${ }^{8}$ Owing to these many resources, smartphones have rapidly become commonplace in modern society. ${ }^{7}$ Nevertheless, the clinical use of smartphones for assessing spinal movements must be based on reliability and validity evidence, which guarantees exact measures and consistent reproduction of results over time. 
In this context, it is important to evaluate the applicability of smartphones in assessing the spine and its psychometric properties. Therefore, the purpose of this systematic review was to investigate validity and reliability of smartphones in assessing the kinematics of the human spine at any age, taking the Pearson correlation, intraclass correlation coefficient (ICC), standard error of measurement (SEM) and minimal detectable change (MDC) as psychometric measures. We hypothesize that smartphones will be able to provide valid and reproducible results in assessing spinal motion so that it should be feasible to use them in a clinical setting.

\section{Methods}

\section{Information Sources and Search Strategy}

The study was a systematic review of observational studies. Its methodology followed the recommendations proposed by the Preferred Reporting Items for Systematic Reviews and Meta-Analyzes. ${ }^{10}$ The project was registered on PROSPERO, a database managed by the Center for Reviews and Dissemination of the University of York (http://www.crd.york.ac.uk/PROSPERO/display_record. php?ID=CRD42018092328).

Two independent reviewers performed, in duplicate, the systematic search of scientific articles on MEDLINE (via PubMed), Embase, Scopus, and LILACS (via BIREME) in February 2018. To avoid loss of articles, the reviewers carried out manual searches in the reference lists of the included studies. Figure 1 depicts the search strategy performed on PubMed. The publication year was not specified.

\section{Eligibility Criteria}

The inclusion criteria were established according the PICO framework: Population (human beings), Intervention/Exposition (validation of smartphones), Comparison (not applicable to this review), and Outcome (kinematic assessment). Thus, we included studies that evaluated (1) psychometric properties of smartphones (reproducibility and/or validity); and (2) kinematic variables of the spine, specifically ROM (range of motion), speed, or acceleration. The studies were excluded (1) for not using cellular inertial sensors to perform the evaluation; (2) for not being written in English, Spanish or Portuguese; and (3) if they were literature or systematic reviews. Despite that the inclusion of randomized controlled trials was not restricted on database searches, they were excluded at the screening stage since they involve clinical interventions and do not present the outcomes investigated by this review.

\section{Study Selection and Data Extraction}

In duplicate, the reviewers independently and blindly ( $\mathrm{J}$. A.S and T.S.F) appraised the titles and abstracts. Articles whose abstracts did not contain enough information for inclusion or exclusion were selected for full-text reading. In a second stage, the reviewers entirely evaluated the content of the articles and selected them according to the eligibility criteria. All disagreements were resolved by consensus.

The same reviewers conducted the data extraction of methodological characteristics, results, and assessment of the risk of bias. All disagreements were resolved by consensus. A standard form was previously developed to extract the following data: sample; smartphone application; gold standard; smartphone placement (where the smartphone was attached to the body of the participant); correlation results and range of limits of agreement for validity studies; and correlation, ICC, SEM, and MDC results for reproducibility studies.

\section{Risk of Bias Assessment}

The included studies were assessed for the risk of bias following the validation and reproducibility critical appraisal scale. ${ }^{11}$ This scale consists of a 13-criteria checklist, whose answers are "yes," "no," or "not applicable." Questions 3, 7, 9, and 11 are only applied to concurrent validity studies; questions $4,5,6$, and 8 are only applied to reproducibility studies; and the other questions are applied to both studies. There is no cutoff point to define the risk of bias of the studies. ${ }^{12}$ So we set a cutoff point of $75 \%$, and

\begin{tabular}{|c|c|}
\hline$\# 1$ & $\begin{array}{l}\text { Search ("Smartphone" [Mesh] OR "Smartphone" OR "smartphones" OR "smart phones" OR } \\
\text { "smartphone" OR "Phone, Smart" OR "Phones, Smart" OR "iPhone" OR "iPod" OR "Mobile } \\
\text { Applications" OR "Mobile Application" OR "Mobile Apps" OR "Mobile App") }\end{array}$ \\
\hline$\# 2$ & $\begin{array}{l}\text { Search ("Range of Motion, Articular" [Mesh] OR "Range of Motion, Articular" OR "Joint Range } \\
\text { ofMotion" OR "Joint Range" OR "Joint Flexibility" OR "Flexibility, Joint" OR "Range of } \\
\text { Motion" OR "Passive Range of Motion" OR "mobility" OR "speed of movement" OR "movement } \\
\text { speed" OR "velocity" OR "Acceleration" OR "Accelerations") }\end{array}$ \\
\hline$\# 3$ & $\# 1 A$ \\
\hline
\end{tabular}

*Search fields: title/abstract/keywords

Fig I. Search strategy on PubMed. 
the studies were classified as low risk of bias if they met $75 \%$ or more of the applicable items of the checklist.

\section{Data Analysis}

The data were initially analyzed by similarity and were separated into subgroups according to the region of the spine and the analysis (validity/intrarater or interrater reproducibility). Meta-analyses were performed on the Comprehensive Meta-Analysis software (Biostat Inc., Englewood, $\mathrm{NJ}$ ), based on the sample size (n) of the study and correlation result ( $\mathrm{r}$ value) using the random effects model. The results for Pearson correlation or ICC were interpreted as follows: $\leq 0.25$ very low correlation, 0.26 to 0.49 low correlation, 0.50 to 0.69 moderate correlation, 0.70 to 0.89 high correlation, and $\geq 0.90$ very high correlation.

We considered low heterogeneity if the Higgins inconsistency test $\left(\mathrm{I}^{2}\right)$ was $<50 \%$ and moderate/high heterogeneity if $\mathrm{I}^{2} \geq 50 \%$. $^{13}$

\section{RESULTS}

Of the 2651 potentially relevant citations found on the electronic databases and on the searches in the reference lists of the studies, 9 met the inclusion criteria (Fig 2).
Only 1 study did not meet $75 \%$ of the criteria and presented a high risk of bias (Table 1). All studies met the criteria for sample description (question 1), independence between the evaluated test and the reference standard (question 9), description of the evaluated method (question 10), and statistical methods (question 13). A single study scored question 6 (randomization in the order of the examination).

Table 2 summarizes the main methodological aspects of the included studies according the region of assessment (cervical, thoracic, or lumbar spine): sample, ROM, smartphone application, reference instrument, and placement of the smartphone for the evaluation.

Figure 3 presents the results of the meta-analyses for concurrent validity of the smartphone in assessing cervical motion, in relation to the reference instrument. Very high correlation coefficients and small heterogeneity $\left(\mathrm{I}^{2}\right.$ varying from 0.00 to 9.28 ) were observed in the cervical flexion, extension, and lateral flexion. High correlation coefficients and small heterogeneity $\left(\mathrm{I}^{2}=11.86-14.32\right)$ were found in cervical rotation.

Figure 4 presents the results of meta-analyses for intrarater reproducibility from the ICC values of smartphones in assessing cervical flexion, extension, lateral flexion, and cervical rotation. High correlation coefficients and small heterogeneity $\left(\mathrm{I}^{2}=0.00-21.21\right)$ were observed in these movements.

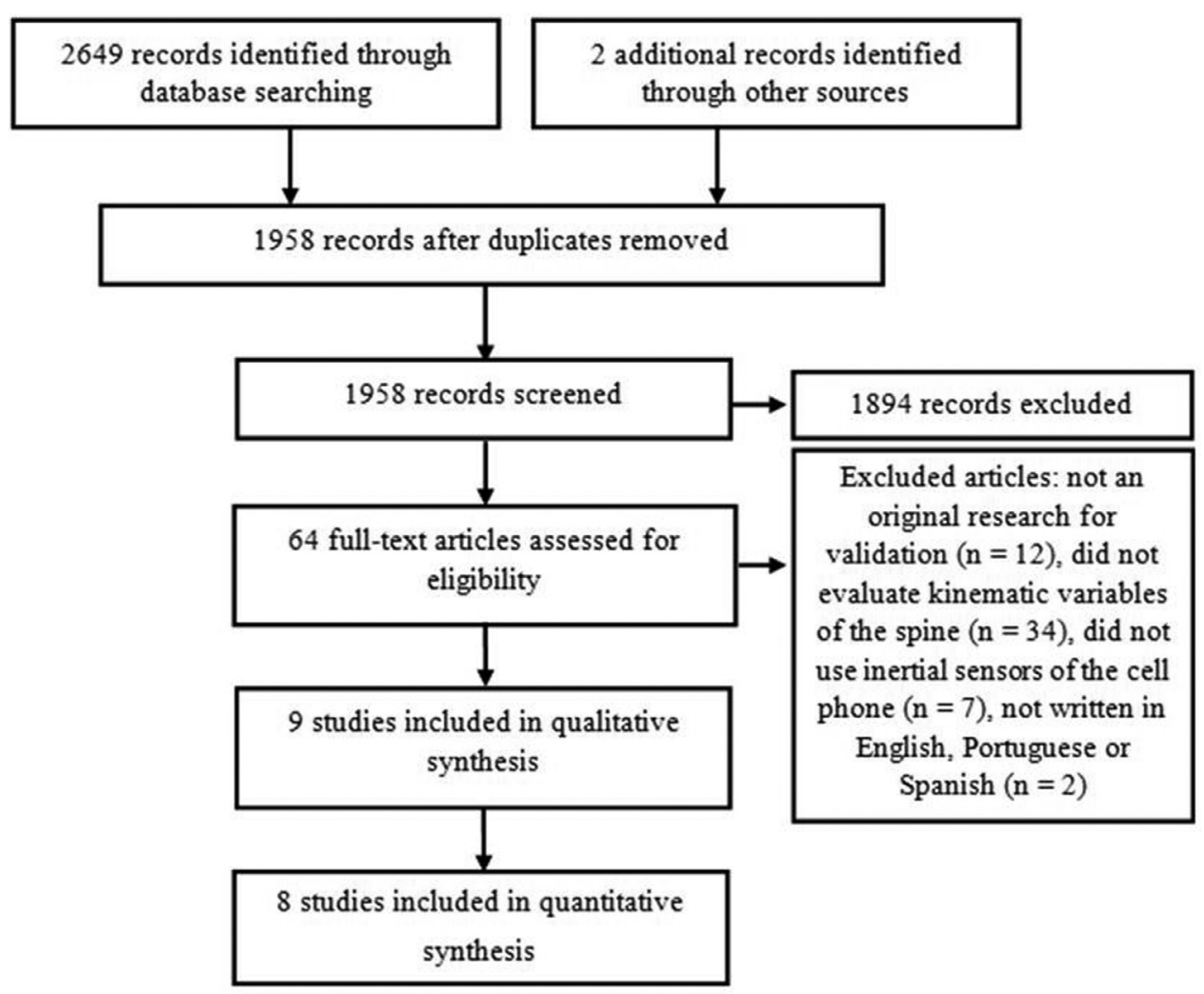

Fig 2. Flow diagram depicting the inclusion of studies, according the PRISMA (Moher et al, 2009). PRISMA, Preferred Reporting Items for Systematic Reviews and Meta-Analyses. 
Table I. Results of the Risk of Bias Assessment, According to the Validation and Reproducibility Critical Appraisal Scale ${ }^{11}$

\begin{tabular}{|c|c|c|c|c|c|c|c|c|c|c|c|c|c|c|c|c|}
\hline First Author (year) & 1 & 2 & 3 & 4 & 5 & 6 & 7 & 8 & 9 & 10 & 11 & 12 & 13 & Number of $\checkmark$ & $\%$ of $\sqrt{ }$ & Risk of Bias \\
\hline Bedekar $(2014)^{19}$ & $\checkmark$ & $\sqrt{ }$ & $\mathrm{X}$ & $\checkmark$ & $\checkmark$ & $\mathrm{X}$ & $\mathrm{X}$ & $\checkmark$ & $\checkmark$ & $\checkmark$ & $\mathrm{X}$ & $\checkmark$ & $\checkmark$ & 9 & 69.2 & High \\
\hline Bucke $(2017)^{14}$ & $\checkmark$ & $\checkmark$ & $\checkmark$ & na & na & na & $\checkmark$ & na & $\checkmark$ & $\checkmark$ & $\checkmark$ & $\mathrm{X}$ & $\checkmark$ & 8 & 88.9 & Low \\
\hline Guidetti $(2017)^{5}$ & $\checkmark$ & $\mathrm{X}$ & $\checkmark$ & $\checkmark$ & $\checkmark$ & $\mathrm{X}$ & $\checkmark$ & $\checkmark$ & $\checkmark$ & $\checkmark$ & $\checkmark$ & $\checkmark$ & $\checkmark$ & 11 & 84.6 & Low \\
\hline Kolber $(2013)^{20}$ & $\checkmark$ & $\checkmark$ & $\mathrm{X}$ & $\checkmark$ & $\checkmark$ & $\mathrm{X}$ & $\checkmark$ & $\checkmark$ & $\checkmark$ & $\sqrt{ }$ & $\checkmark$ & $\checkmark$ & $\checkmark$ & 11 & 84.6 & Low \\
\hline Pourahmadi $(2018)^{6}$ & $\checkmark$ & $\checkmark$ & $\mathrm{X}$ & $\checkmark$ & $\checkmark$ & $X$ & $\checkmark$ & $\checkmark$ & $\checkmark$ & $\checkmark$ & $\checkmark$ & $\checkmark$ & $\checkmark$ & 11 & 84.6 & Low \\
\hline Pourahmadi (2016) ${ }^{15}$ & $\checkmark$ & $\checkmark$ & $\checkmark$ & $\checkmark$ & $\checkmark$ & $\mathrm{X}$ & $\checkmark$ & $\checkmark$ & $\checkmark$ & $\checkmark$ & $\sqrt{ }$ & $\checkmark$ & $\checkmark$ & 12 & 92.3 & Low \\
\hline Quek (2014) ${ }^{16}$ & $\checkmark$ & $\checkmark$ & $\checkmark$ & na & $\mathrm{X}$ & $\mathrm{X}$ & $\checkmark$ & $\checkmark$ & $\checkmark$ & $\sqrt{ }$ & $\sqrt{ }$ & $\checkmark$ & $\checkmark$ & 10 & 83.3 & Low \\
\hline Stenneberg $(2018)^{17}$ & $\checkmark$ & $\checkmark$ & $\checkmark$ & $\sqrt{ }$ & na & $\checkmark$ & $\checkmark$ & $\checkmark$ & $\checkmark$ & $\checkmark$ & $\checkmark$ & $\checkmark$ & $\checkmark$ & 12 & 100 & Low \\
\hline Tousignant-Laflamme $(2013)^{18}$ & $\checkmark$ & $\checkmark$ & $\checkmark$ & $\sqrt{ }$ & $\checkmark$ & $X$ & $\checkmark$ & $\checkmark$ & $\checkmark$ & $\checkmark$ & $\sqrt{ }$ & $X$ & $\sqrt{ }$ & 11 & 84.6 & Low \\
\hline
\end{tabular}

Criteria: (1) Did the authors give a detailed description of the sample? (2) Did the authors clarify the qualification or competence of the rater(s)? (3) Was the reference standard explained? (4) If inter-rater reliability was tested, were raters blinded to the findings of other raters? (5) If intrarater reliability was tested, were raters blinded to their own prior findings? (6) Was the order of examination randomized? (7) Was the period between the reference standard and the evaluated test short enough to be reasonably sure that the target condition did not change between the 2 tests? (8) Was the stability of the variable being measured taken into account when determining the suitability of the time interval between repeated measures? (9) Was the reference standard independent of the evaluated test? (10) Was the execution of the evaluated test described in sufficient detail to permit replication of the test? (11) Was the execution of the reference standard described in sufficient detail to permit its replication? (12) Were withdrawals from the study explained? (13) Were the statistical methods appropriate for the purpose of the study?

$\checkmark$, yes; $X$, no; na, not applicable.

Figure 5 presents the results of meta-analyses for interrater reproducibility from the ICC values of smartphones in assessing cervical flexion, extension, lateral flexion, and rotation. High correlation coefficients and small heterogeneity $\left(\mathrm{I}^{2}=7.27-9.81\right)$ were observed between these movements.

We could not analyze data from the thoracic region since only 1 study approached this region. ${ }^{14}$ This study obtained $r=0.88$ and a CI range of $28.6^{\circ}$ for concurrent validity of the smartphone in assessing thoracic rotation.

Regarding lumbar assessments, we could only analyze data from lumbar flexion (Fig 6). High correlation coefficients and small heterogeneity $\left(\mathrm{I}^{2}=0.00\right)$ were observed between the correlation of smartphones and the reference instrument (validity evidence) and for interrater reproducibility. Very high correlation coefficients and small heterogeneity $\left(\mathrm{I}^{2}=0.00\right)$ were obtained for the intrarater reproducibility. Only 1 study analyzed the lumbar extension assessment and found very high correlation $(r=0.91) .^{15}$

Table 3 demonstrate the results of the limits of agreement obtained for concurrent validity of the smartphone, and also the results from SEM and MDC values for the intrarater and interrater reproducibility data.

\section{DISCUSSION}

Nine studies investigated the validity and reproducibility of smartphones in assessing kinematic characteristics of spinal movement. Only the ROM assessment was analyzed, as the studies did not approach other kinematic aspects such as movement speed and acceleration.

Five studies approached validation aspects of the cervical region, but each one used a different smartphone application. The risk of bias of these studies was low. Based on the data obtained in the meta-analyses, the smartphones presented very high correlation with the reference instruments used in the evaluation of cervical flexion, extension, and lateral flexion. Three studies showed a small range of the CIs for these movements. ${ }^{5,16,17}$

Cervical rotation also presented high correlation coefficients, despite obtaining smaller scores compared with the other movements. Possibly these scores were influenced by the study of Tousignant-Laflamme et al (2013), which presented the smallest correlation values for cervical rotation $\left(r=0.58 / r=0.38\right.$; right/left rotations, respectively). ${ }^{18}$ When observing the range of limits of agreement for the evaluation of cervical rotation, an adequate range was found $\left(2.8^{\circ}\right.$ for left rotation and $2.4^{\circ}$ for right rotation) only in the study from Guidetti et al (2017). ${ }^{5}$ The study by TousignantLaflamme et al (2013) does not present these analyses. ${ }^{18}$

Based on the results of the meta-analyses, all cervical movements presented high ICCs and low heterogeneity regarding the intrarater reproducibility. In addition, the SEM and the MDC values, which reflect the error associated with the measure, confirm intrarater reproducibility of smartphones for cervical assessment. All SEM values were smaller than $5^{\circ}$, except for the assessment of cervical rotation in the study by Quek et al (2014). ${ }^{16}$ The MDC values 
Table 2. Methodological Aspects of the Studies

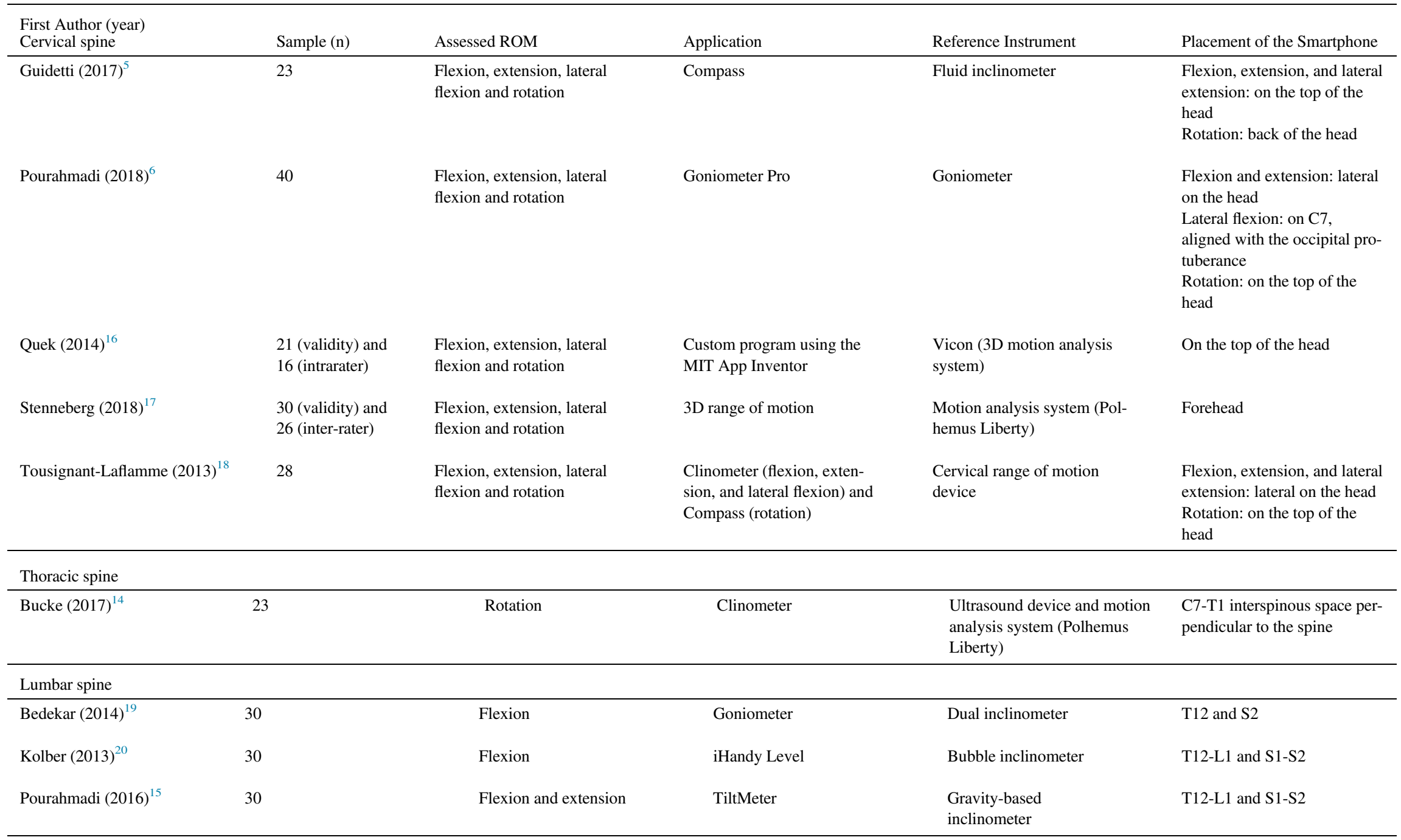

3D, 3-dimensional; MIT, Massachusetts Institute of Technology; ROM, range of motion. 


\begin{tabular}{|c|c|c|c|c|c|c|c|c|c|c|}
\hline Study (year) & Correlation & $95 \% \mathrm{CI}$ & $Z$ value & $\mathrm{p}$ value & n & $I^{2}(\%)$ & \multicolumn{4}{|c|}{ Conrelation $(95 \% \mathrm{CI})$} \\
\hline \multicolumn{7}{|c|}{ Flexion } & & \multirow[b]{2}{*}{ 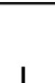 } & & \\
\hline Guidetti (2017) & 0.990 & $0.976-0.996$ & 11.836 & 0.000 & 23 & & & & & \\
\hline Pourahmadi (2018) & 0.630 & $0.416-0.778$ & 4.862 & 0.000 & 46 & & \multirow{5}{*}{-1.00} & \multirow{5}{*}{-0.50} & & \\
\hline Quek (2014) & 0.990 & $0.975-0.996$ & 11.229 & 0.000 & 21 & & & & \multirow{4}{*}{0.00} & \multirow{4}{*}{0.50} \\
\hline Stennberg (2018) & 0.910 & $0.810-0.959$ & 7.483 & 0.000 & 27 & & & & & \\
\hline \multirow[t]{2}{*}{\begin{tabular}{|l|} 
Tousignant-Laflamme (2013) \\
\end{tabular}} & 0.690 & $0.427-0.845$ & 4.240 & 0.000 & 28 & & & & & \\
\hline & 0.932 & $0.699-0.986$ & 4.066 & $0.000^{*}$ & & 2.279 & & & & \\
\hline \multicolumn{7}{|c|}{ Extension } & & & & \\
\hline Guidetti (2017) & 0.999 & $0.998-1.000$ & 16.995 & 0.000 & 23 & & \multirow{6}{*}{-1.00} & & & \\
\hline Pourahmadi (2018) & 0.810 & $0.679-0.891$ & 7.390 & 0.000 & 46 & & & & & \\
\hline Quek (2014) & 0.830 & $0.621-0.929$ & 5.041 & 0.000 & 21 & & & & & \\
\hline Stenuberg $(2018)$ & 0.990 & $0.978-0.995$ & 12.966 & 0.000 & 27 & & & & & \\
\hline \multirow[t]{2}{*}{ Tousignant-Laflamme (2013) } & 0.560 & $0.236-0.772$ & 3.164 & 0.002 & 28 & & & & & \\
\hline & 0.954 & $0.654-0.995$ & 3.363 & $0.001^{*}$ & & 9.282 & & -0.50 & 0.00 & \\
\hline \multicolumn{7}{|c|}{ Right lateral flexion } & & & & \\
\hline Guidetti (2017) & 0.990 & $0.976-0.996$ & 11.836 & 0.000 & 23 & & \multirow{6}{*}{$\left.\right|_{-1.00}$} & 1 & 1 & \\
\hline Pourahmadi (2018) & 0.790 & $0.648-0.879$ & 7.026 & 0.000 & 46 & & & & & \\
\hline Quek (2014) & 0.930 & $0.833-0.972$ & 7.036 & 0.000 & 21 & & & & & \\
\hline Stennberg $(2018)$ & 0.980 & $0.958-0.991$ & 11.938 & 0.000 & 30 & & & & & \\
\hline \multirow[t]{2}{*}{ Tousignant-Laflamme (2013) } & 0.800 & $0.609-0.903$ & 5.493 & 0.000 & 28 & & & & & \\
\hline & 0.941 & $0.807-0.983$ & 5.440 & $0.000^{*}$ & & 0.000 & & -0.50 & 0.00 & \\
\hline \multicolumn{7}{|c|}{ Left lateral flexion } & & & & \\
\hline Guidetti (2017) & 0.990 & $0.976-0.996$ & 11.836 & 0.000 & 23 & & \multirow{6}{*}{$\left.\right|_{-1.00}$} & & & \\
\hline Pourahmadi (2018) & 0.720 & $0.543-0.836$ & 5.952 & 0.000 & 46 & & & & & \\
\hline Quek (2014) & 0.920 & $0.810-0.967$ & 6.742 & 0.000 & 21 & & & & & \\
\hline Stennberg (2018) & 0.990 & $0.979-0.995$ & 13.752 & 0.000 & 30 & & & & & \\
\hline \multirow[t]{2}{*}{ Tousignant-Laflamme (2013) } & 0.630 & $0.336-0.812$ & 3.707 & 0.000 & 28 & & & & 1 & \\
\hline & 0.936 & $0.707-0.987$ & 4.064 & $0.000^{*}$ & & 0.000 & & -0.50 & 0.00 & \\
\hline \multicolumn{7}{|c|}{ Right rotation } & & & & \\
\hline Guidetti (2017) & 0.990 & $0.976-0.996$ & 11.836 & 0.000 & 23 & & , & & 1 & \\
\hline Pourahmadi(2018) & 0.750 & $0.588-0.854$ & 6.380 & 0.000 & 46 & & & & & \\
\hline Quek (2014) & 0.810 & $0.582-0.920$ & 4.782 & 0.000 & 21 & & & & & \\
\hline Stennberg (2018) & 0.910 & $0.815-0.957$ & 7.789 & 0.000 & 29 & & & & & \\
\hline \multirow[t]{2}{*}{ Tousignant-Laflamme (2013) } & 0.580 & $0.264-0.784$ & 3.312 & 0.001 & 28 & & 1.00 & 0.50 & 0.00 & 0.50 \\
\hline & 0.881 & $0.636-0.965$ & 4.293 & $0.000^{*}$ & & 11.858 & & & & \\
\hline & & ft rotation & & & & & & & & \\
\hline Guidetti (2017) & 0.990 & $0.976-0.996$ & 11.836 & 0.000 & 23 & & & & & \\
\hline Pourahmadi (2018) & 0.770 & $0.618-0.867$ & 6.691 & 0.000 & 46 & & & & & \\
\hline Quek (2014) & 0.520 & $0.114-0.777$ & 2.445 & 0.014 & 21 & & & & & \\
\hline Stennberg $(2018)$ & 0.950 & $0.895-0.977$ & 9.340 & 0.000 & 29 & & & & & \\
\hline Tousignant-Laflamme (2013) & 0.380 & $0.008-0.660$ & 2.000 & 0.045 & 28 & & 1 & & & \\
\hline & 0.860 & $0.490-0.967$ & 3.349 & $0.001 *$ & & 14.323 & -1.00 & -0.50 & 0.00 & \\
\hline
\end{tabular}

Fig 3. Cervical movements: meta-analyses of correlation values between smartphones and reference instruments (concurrent validity).

were generally smaller than $10^{\circ}$, except in the study by Quek et al (2014), which presented MDC values greater than $10^{\circ}$ in the assessment of cervical extension, left lateral flexion, and rotation, being the worst results obtained for cervical rotation $\left(\mathrm{MDC}=46.9^{\circ} / 48.7^{\circ}\right.$ for left and right rotation, respectively). ${ }^{16}$

In this way, when assessing cervical rotation, it seems more appropriate to attach the smartphone at the posterior region of the head, ${ }^{5}$ as Tousignant-Laflamme et al (2013) did not find valid and reproducible results placing it at the top of the head. ${ }^{18}$

Similar results were obtained in the evaluation of the interrater reproducibility, since the meta-analyses demonstrated high ICC values and low heterogeneity for all cervical movements. The results for the SEM and the MDC values reaffirm the interrater reproducibility of smartphones, 


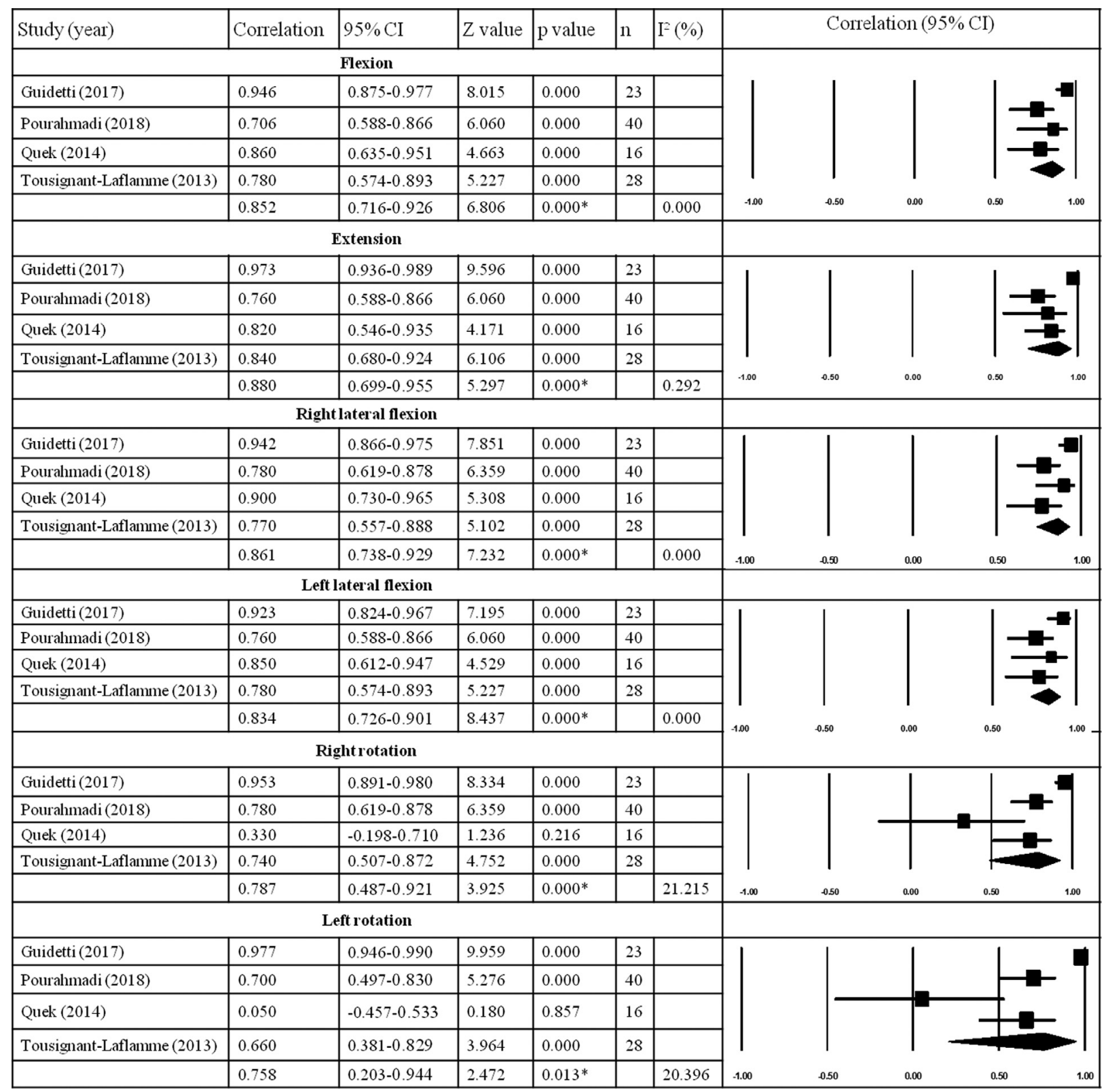

Fig 4. Cervical movements: meta-analyses of ICC values (intrarater reproducibility). ICC, intraclass correlation coefficient.

since in all cases the SEM values were smaller than $5^{\circ}$ and the MDC values were smaller than $10^{\circ}$.

Despite the low heterogeneity found in the meta-analyses, differences in the results between the studies can be noticed, which may be associated with methodological differences such as distinct reference instruments (gold standard), different measurement protocol, and different placement of the smartphone for the evaluation. Each study analyzed aspects of validity of a different application, which may also contribute to the differences in the results.

Only 1 study investigated the thoracic region. It analyzed the concurrent validity for the rotational movement using the
Clinometer application to evaluate this region. ${ }^{14}$ Although its results showed high correlation $(r=0.88)$ for concurrent validity, the use of this application for thoracic assessment is still incipient. Furthermore, it does not describe the reproducibility of the application. In addition, this study presented a wide range of limits of agreement $\left(28.6^{\circ}\right)$, demonstrating low agreement with the reference instrument. Thus, it is still necessary to approach other movements of the thoracic region and its aspects of validation to allow a safe use of the smartphone as tool for assessing this segment.

Lumbar flexion was approached by 3 studies, which described 3 different applications. ${ }^{15,19,20}$ They evaluated 


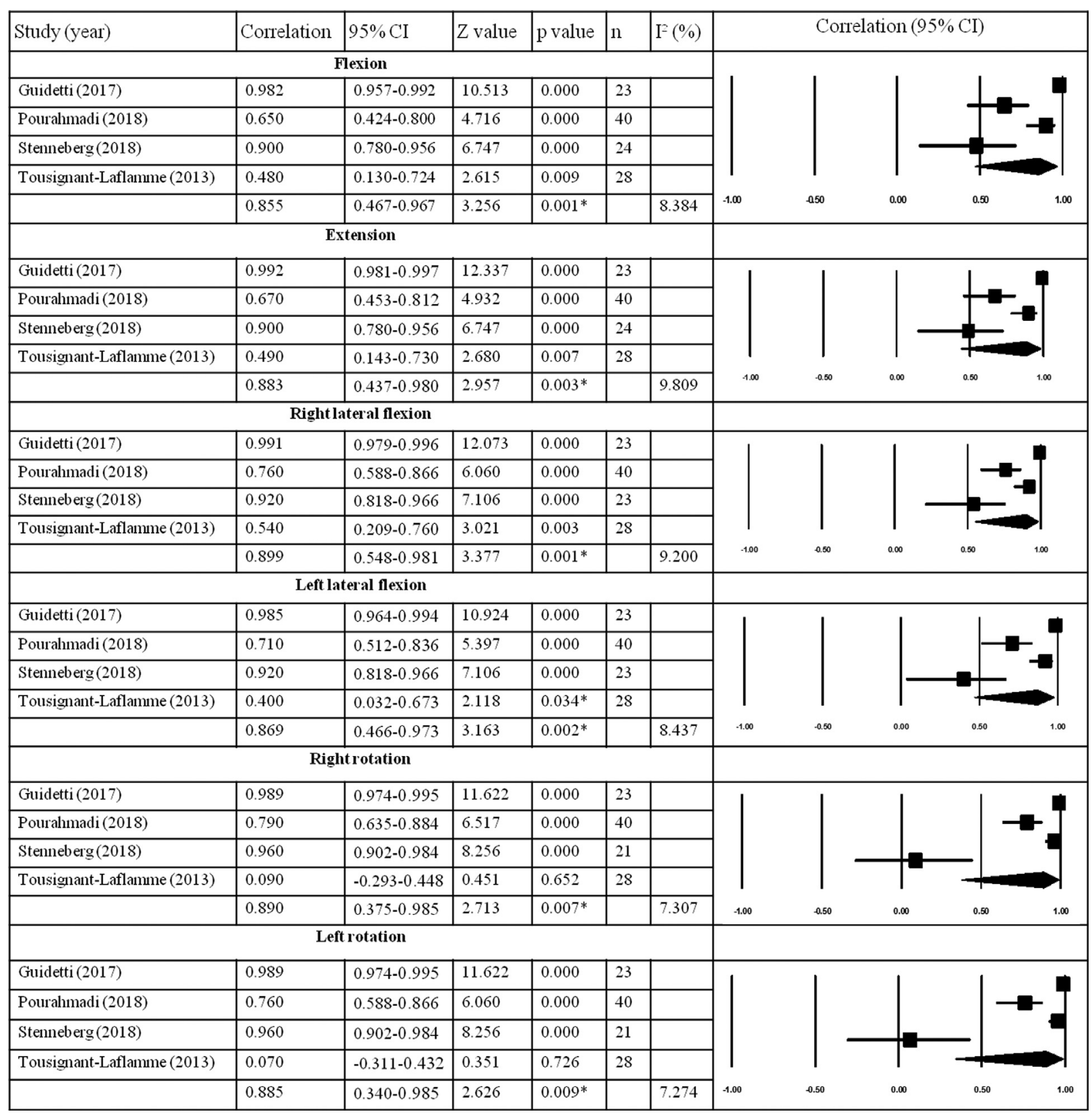

Fig 5. Cervical movements: meta-analyses of ICC values (interrater reproducibility). ICC, intraclass correlation coefficient.

lumbar flexion, but only 1 also evaluated lumbar extension. ${ }^{15}$ Of these studies, only 1 presented a high risk of bias. In the meta-analysis, high correlation values and low heterogeneity $\left(\mathrm{I}^{2}=0.00\right)$ were obtained by analyzing the smartphone correlation with the reference instruments used in the evaluation of lumbar flexion. However, the agreement in the lumbar flexion evaluation should be analyzed with caution, since these studies demonstrated limits of agreement ranging from $13.1^{\circ}$ to $25^{\circ}$.

The meta-analysis results for the interrater reproducibility of lumbar flexion presented very high ICC values and low heterogeneity $\left(\mathrm{I}^{2}=0.00\right)$ and for the intrarater reproducibility, high ICC values and low heterogeneity $\left(I^{2}=0.00\right)$. In addition, only 1 study reported SEM (smaller than $3.1^{\circ}$ ) and MDC (smaller than $8.7^{\circ}$ ) for both intrarater and interrater reproducibility. ${ }^{15}$ Studies focusing on the investigation of validity aspects should include in-depth analyses as limits of agreement, SEM, and MDC, besides correlation analyses. However, many authors still prioritize the correlation results and the data are superficially demonstrated.

Only Pourahmadi et al (2016) investigated validity aspects of lumbar extension and obtained suitable results for concurrent validity as well as for intrarater and interrater 


\begin{tabular}{|c|c|c|c|c|c|c|c|c|c|c|c|}
\hline Study (year) & Correlation & $95 \% \mathrm{IC}$ & $Z$ value & p value & $n$ & $\mathrm{I}^{2}(\%)$ & \multicolumn{5}{|c|}{ Correlation $(95 \% \mathrm{CI})$} \\
\hline \multicolumn{7}{|c|}{ Correlation with the reference instrument } & \multirow{5}{*}{$\left.\right|_{-1.00}$} & \multirow[b]{5}{*}{-0.50} & \multirow[b]{5}{*}{ a00 } & \multirow[b]{5}{*}{0.50} & \\
\hline Bedekar (2014) & 0.950 & $0.897-0.976$ & 9.518 & 0.000 & 30 & & & & & & \\
\hline Kolber (2013) & 0.865 & $0.733-0.934$ & 6.822 & 0.000 & 30 & & & & & & \\
\hline \multirow[t]{2}{*}{ Pourahmad (2016) } & 0.850 & $0.706-0.927$ & 6.527 & 0.000 & 30 & & & & & & \\
\hline & 0.899 & $0.803-0.949$ & 8.009 & $0.000^{*}$ & & 0.000 & & & & & 1.00 \\
\hline \multicolumn{7}{|c|}{ Intra-rater reproducibility } & & & & & \\
\hline Bedekar (2014) & 0.920 & $0.837-0.962$ & 8.257 & 0.000 & 30 & & \multirow{4}{*}{$\left.\right|_{1.00}$} & & & & \\
\hline Kolber (2013) & 0.880 & $0.761-0.942$ & 7.149 & 0.000 & 30 & & & & & & \\
\hline \multirow[t]{2}{*}{ Pourahmad (2016) } & 0.920 & $0.837-0.962$ & 8.257 & 0.000 & 30 & & & & & & \\
\hline & 0.908 & $0.862-0.940$ & 13.661 & $0.000^{*}$ & & 0.000 & & -0.50 & 0.00 & 0.50 & 1.00 \\
\hline \multicolumn{7}{|c|}{ Inter-rater reproducibility } & & & & & \\
\hline Bedekar (2014) & 0.810 & $0.635-0.906$ & 5.856 & 0.000 & 30 & & \multirow{4}{*}{$\left.\right|_{-1.00}$} & & & & \\
\hline Kolber (2013) & 0.880 & $0.761-0.942$ & 7.149 & 0.000 & 30 & & & & & & \\
\hline \multirow[t]{2}{*}{ Pourahmad (2016) } & 0.850 & $0.706-0.927$ & 6.527 & 0.000 & 30 & & & & & & \\
\hline & 0.849 & $0.776-0.900$ & 11.277 & $0.000^{*}$ & & 0.000 & & -0.50 & 0.00 & 0.50 & 1.00 \\
\hline
\end{tabular}

Fig 6. Lumbar flexion: meta-analyses of correlation values between the smartphone and the reference instrument (concurrent validity), and ICC values (intrarater and interrater reproducibility). ICC, intraclass correlation coefficient.

Table 3. Results of the Limits of Agreement for Concurrent Validity and SEM and MDC Values for the Intrarater and Interrater Reproducibility

\begin{tabular}{|c|c|c|c|c|c|}
\hline \multirow[b]{2}{*}{ Author (year) } & \multirow{2}{*}{$\begin{array}{l}\text { Concurrent Validity } \\
\text { Limits of Agreement }\end{array}$} & \multicolumn{2}{|c|}{ Intrarater Reproducibility } & \multicolumn{2}{|c|}{ Interrater Reproducibility } \\
\hline & & $\overline{\operatorname{SEM}\left({ }^{\circ}\right)}$ & $\operatorname{MDC}\left({ }^{\circ}\right)$ & $\overline{\mathrm{SEM}\left({ }^{\circ}\right)}$ & $\operatorname{MDC}\left({ }^{\circ}\right)$ \\
\hline \multicolumn{6}{|l|}{ Cervical spine } \\
\hline Guidetti $(2017)^{5}$ & $\begin{array}{l}\text { Flexion: } 1.4 ; \text { exten- } \\
\text { sion: } 1.6 \text {; LLF: } 2.9 \text {; } \\
\text { RLF: } 2.1 \text {; LR: } 2.8 ; \\
\text { RR: } 2.4\end{array}$ & $\begin{array}{l}\text { Flexion: } 2.5 \text {; exten- } \\
\text { sion: } 2.7 \text {; LLF: } 2.4 \text {; } \\
\text { RLF: } 2.3 \text {; LR: } 1.6 \text {; } \\
\text { RR: } 1.9\end{array}$ & $\begin{array}{l}\text { Flexion:7; exten- } \\
\text { sion:7; LLF: 7; RLF: } \\
\text { 6; LR: 4; RR: } 5\end{array}$ & $\begin{array}{l}\text { Flexion: } 2 \text {; exten- } \\
\text { sion:2; LLF: } 1.5 ; \\
\text { RLF: } 1.4 ; \text { RR: } 1.5 \text {; } \\
\text { LR: } 1.5\end{array}$ & $\begin{array}{l}\text { Flexion: 6; extension: } \\
\text { 6; LLF: 4; RLF: 4; } \\
\text { LR: 4; RR: } 4\end{array}$ \\
\hline Pourahmadi $(2018)^{6}$ & $\begin{array}{l}\text { Flexion: } 22.4 \text {; exten- } \\
\text { sion: } 11.3 \text {; LLF: } 6.2 \text {; } \\
\text { RLF: } 7.8 \text {; LR: } 20.7 \text {; } \\
\text { RR: } 22.4\end{array}$ & $\begin{array}{l}\text { Flexion: } 2.5 \text {; exten- } \\
\text { sion: } 2.4 \text {; LLF: } 1 \text {; } \\
\text { RLF: } 1.4 \text {; LR: } 3.5 \text {; } \\
\text { RR: } 3.6\end{array}$ & $\begin{array}{l}\text { Flexion:6.9; exten- } \\
\text { sion:6.6; LLF: } 2.8 \\
\text { RLF: } 3.9 ; \text { LR: } 9.8 \\
\text { RR: } 9.9\end{array}$ & $\begin{array}{l}\text { Flexion:2.8; exten- } \\
\text { sion:2.7; LLF: } 2.1 \text {; } \\
\text { RLF: } 1.5 \text {; RR: } 3.3 \text {; } \\
\text { LR: } 3.5\end{array}$ & $\begin{array}{l}\text { Flexion: } 7.7 \text {; exten- } \\
\text { sion: } 7.6 \text {; LLF: } 5.9 \text {; } \\
\text { RLF: 4.1; RR: } 9.1 \text {; } \\
\text { LR: } 9.7\end{array}$ \\
\hline Quek $(2014)^{16}$ & $\begin{array}{l}\text { Flexion: 2.3; exten- } \\
\text { sion: 9.6; LLF: 7.1; } \\
\text { RLF: 4.6; LR: 18.6; } \\
\text { RR: 9.6 }\end{array}$ & $\begin{array}{l}\text { Flexion:3.1; exten- } \\
\text { sion:5; LLF: } 4.1 ; \\
\text { RLF: } 2.8 ; \text { LR: } 15.8 \text {; } \\
\text { RR: } 16.4\end{array}$ & $\begin{array}{l}\text { Flexion: } 9.2 \text {; exten- } \\
\text { sion: } 11.9 \text {; LLF: } 12.2 \text {; } \\
\text { RLF: } 8.3 \text {; LR: } 46.9 ; \\
\text { RR: } 48.7\end{array}$ & N/A & N/A \\
\hline Stenneberg $(2018)^{17}$ & $\begin{array}{l}\text { Flexion: 6.6; exten- } \\
\text { sion: } 6.7 \text {; LLF: } 5.7 \text {; } \\
\text { RLF: 5.3; LR: } 8.2 ; \\
\text { RR: } 8.7\end{array}$ & N/A & N/A & N/A & N/A \\
\hline $\begin{array}{l}\text { Tousignant-Laflamme } \\
(2013)^{18}\end{array}$ & N/A & N/A & N/A & N/A & N/A \\
\hline \multicolumn{6}{|l|}{ Lumbar spine } \\
\hline Bedekar $(2014)^{19}$ & N/A & N/A & N/A & N/A & N/A \\
\hline Kolber $(2013)^{20}$ & Flexion: 25 & N/A & N/A & N/A & Flexion: 8 \\
\hline Pourahmadi (2016) ${ }^{15}$ & $\begin{array}{l}\text { Flexion: } 13.1 \text {; exten- } \\
\text { sion: } 10.3\end{array}$ & $\begin{array}{l}\text { Flexion: } 2.4 \text {; exten- } \\
\text { sion: } 2.2\end{array}$ & $\begin{array}{l}\text { Flexion: } 6.7 \text {; exten- } \\
\text { sion: } 6.2\end{array}$ & $\begin{array}{l}\text { Flexion: } 3.1 \text {; exten- } \\
\text { sion: } 2.7\end{array}$ & $\begin{array}{l}\text { Flexion: } 8.7 \text {; exten- } \\
\text { sion: } 7.4\end{array}$ \\
\hline
\end{tabular}


reproducibility. ${ }^{15}$ However, further studies investigating this movement are required so that smartphones can be safely used for this assessment.

Methodological differences were also identified among the studies investigating the lumbar region, mainly owing to the use of different applications. Despite this, all studies attached the smartphone at the same place (T12-L1 and S1S2) for the evaluation and subtraction of the angular values to obtain lumbar ROM.

\section{Limitations}

As a limitation of the study, potentially relevant articles may not have been considered owing to language restriction since only English, Spanish, and Portuguese articles were included. A second limitation may be the miscellany of applications, which hinders comparison among the studies.

From this review it was possible to verify that, in the last 5 years, the interest in using and validating smartphones for the assessment of human movement has arisen. This is possibly because these instruments have the capacity to instantly provide quantifiable data, besides being an accessible technology to most people, enabling their implementation in the clinical setting. ${ }^{21}$ Thus, we understand that our study contributes to the human movement sciences when it confirms the validity and reliability of smartphones in assessing the kinematics of spinal movement. This result may encourage the use of this instrument in field research rather than studies conducted at a laboratory. In addition, the clinical relevance of our study resides in motivating the clinician to use instruments that provide accurate (valid) and precise (reproducible) measures of spinal movements. Therefore, based on this systematic review, it is possible to consider that smartphones so far present adequate validity and intrarater and interexaminer reproducibility in assessing cervical flexion, extension, lateral flexion and rotations, and lumbar flexion.

Despite this, we understand that there is a demand for investigation concerning distinct populations (ie, children, people with severe limited ROM, etc.) not included in the studies conducted so far. Therefore, in the literature, there is still a lack of studies investigating psychometric properties of smartphones in assessing spinal kinematics.

\section{CONCLUSION}

Nowadays, it is possible to implement the use of smartphones for assessing the ROM of cervical flexion, extension, and lateral flexion and lumbar flexion. In addition, smartphones are potentially viable for assessing thoracic rotation and lumbar extension. Nevertheless, further validation studies are still necessary for safe use of these instruments to evaluate these regions. Furthermore, there is a lack of validation studies for the evaluation of the applicability of smartphones in assessing other kinematic characteristics, such as speed and acceleration.

\section{Funding SOURCES AND CONFLICTS OF INTEREST}

No funding sources or conflicts of interest were reported for this study.

\section{CONTRIBUTORSHIP INFORMATION}

Concept development (provided idea for the research): J.A.S., T.S.F., G.M.G., C.T.C.

Design (planned the methods to generate the results): J.A.S., T.S.F., G.M.G., C.T.C.

Supervision (provided oversight, responsible for organization and implementation, writing of the manuscript): C.T.C. Data collection/processing (responsible for experiments, patient management, organization, or reporting data): J.A.S., T.S.F.

Analysis/interpretation (responsible for statistical analysis, evaluation, and presentation of the results) : J.A.S., T.S.F., G.M.G., C.T.C.

Literature search (performed the literature search): J.A.S., T.S.F.

Writing (responsible for writing a substantive part of the manuscript): J.A.S., T.S.F.

Critical review (revised manuscript for intellectual content, this does not relate to spelling and grammar checking): G.M.G., C.T.C.

\section{Practical Applications}

- The use of smartphones for assessing the ROM of lumbar flexion is feasible.

- The use of smartphones for assessing the ROM of cervical movements is feasible.

- Their use for assessing thoracic rotation is potentially viable.

\section{REFERENCES}

1. GBD 2016 Disease and Injury Incidence and Prevalence Collaborators. Global, regional, and national incidence, prevalence, and years lived with disability for 328 diseases and injuries for 195 countries, 1990-2016: a systematic analysis for the Global Burden of Disease Study 2016. Lancet. 2017;390(10100):1211-1259.

2. Christe G, Redhead L, Legrand T, Jolles BM, Favre J. Multisegment analysis of spinal kinematics during sit-to-stand in patients with chronic low back pain. J Biomech. 2016;49 (10):2060-2067. 
3. Alba-Martín R. Fiabilidade y validez de las mediciones em hombro y codo: análisis de uma aplicación de Android y um goniómetro. Reabilitación. 2016;50(2):71-74.

4. Belyea BC, Lewis E, Gabor Z, Jackson J, King DL. Validity and intra-rater reliability of 2-dimensional motion analysis using a hand-held tablet compared to traditional 3-dimensional motion analysis. J Sport Rehabil. 2015;24(4):1-7.

5. Guidetti L, Placentino U, Baldari C. Reliability and criterion validity of the smartphone inclinometer application to quantify cervical spine mobility. Clin Spine Surg. 2017;30(10): E1359-E1366.

6. Pourahmadi MR, Bagheri R, Taghipour M, Takamjani IE, Sarrafzadeh J, Mohseni-Bandpei MA. A new iPhone application for measuring active craniocervical range of motion in patients with non-specific neck pain: a reliability and validity study. Spine J. 2018;18(3):447-457.

7. Del Rosario MB, Redmond SJ, Lovell NH. Tracking the evolution of smartphone sensing for monitoring human movement. Sensors. 2015;15(8):18901-18933.

8. Ockendon M, Gilbert RE. Validation of a novel smartphone accelerometer-based knee goniometer. J Knee Surg. 2012;25 (4):341-345.

9. Boissy P, Diop-Fallou S, Lebel K, Bernier M, Balg F, Tousignant-Laflamme Y. Trueness and minimal detectable change of smartphone inclinometer measurements of shoulder range of motion. Telemed J E Health. 2017;23(6):503-506.

10. Moher D, Liberati A, Tetzlaff J, Altman DG. Preferred reporting items for systematic reviews and meta-analyses: the PRISMA statement. PLoS Med. 2009;6(7):1-6.

11. Brink Y, Louw QA. Clinical instruments: reliability and validity critical appraisal. J Eval Clin Pract. 2012;18(6): 1126-1132.

12. Rondoni A, Rossettini G, Ristori D, et al. Intrarater and interrater reliability of active cervical range of motion in patients with nonspecific neck pain measured with technological and common use devices: a systematic review with meta-regression. J Manipulative Physiol Ther. 2017;40(8):597-608.

13. Higgins J, Green S. Cochrane Handbook for Systematic Reviews of Interventions. John Wiley \& Sons, Ltd; 2011.

14. Bucke J, Spencer S, Fawcett L, Sonvico L, Rushton A, Heneghan NR. Validity of the digital inclinometer and iPhone when measuring thoracic spine rotation. J Athletic Train. 2017;52(9):820-825.

15. Pourahmadi MR, Taghipour M, Jannati E, Mohseni-Bandpei MA, Takamjani IE, Rajabzadeh F. Reliability and validity of an iPhone ${ }^{\circledR}$ application for the measurement of lumbar spine flexion and extension range of motion. Peer J. 2016;4:e2355.

16. Quek J, Brauer SG, Treleaven J, Pua YH, Mentiplay B, Clark RA. Validity and intra-rater reliability of an Android phone application to measure cervical range-of-motion. J Neuroeng Rehabil. 2014;11:65.

17. Stenneberg MS, Busstra H, Eskes M, et al. Concurrent validity and interrater reliability of a new smartphone application to assess 3D active cervical range of motion in patients with neck pain. Musculoskelet Sci Pract. 2018;34:59-65.

18. Tousignant-Laflamme Y, Boutin N, Dion AM, Vallée CA. Reliability and criterion validity of 2 applications of the $\mathrm{iPhone}^{\mathrm{TM}}$ to measure cervical range of motion in healthy participants. J Neuroeng Rehabil. 2013;10(1):69.

19. Bedekar N, Suryawanshi M, Rairikar S, Sancheti P, Shyam A. Inter and intra-rater reliability of mobile device goniometer in measuring lumbar flexion range of motion. J Back Musculoskelet Rehabil. 2014;27(2):161-166.

20. Kolber MJ, Pizzini M, Robinson A, Yanez D, Hanney WJ. The reliability and concurrent validity of measurements used to quantify lumbar spine mobility: an analysis of an iPhone ${ }^{\circledR}$ application and gravity based inclinometry. Int J Sports Phys Ther. 2013;8(2):129-137.

21. Dean JM, Silverman M. The utilization of smartphone devices to enhance clinical interventions. Mov Disord. 2015;30:S463. 